\title{
Research on the Education and Training Mode of Innovative Talents of New Engineering in Colleges and Universities
}

\author{
Yan Li \\ Xi'an Fanyi University \\ Xi'an, China 710105
}

\begin{abstract}
With the launching of the construction plan of "new engineering", the research and discussion about new engineering in China is unprecedentedly active. And practical exploration is already on the way. This paper reviews the literature on new engineering, the characteristics of new engineering and so on, clarifies the relationship between the new engineering and the old engineering, new engineering economy, the requirements of the new engineering for the innovative talents, analyzes the shortage of the training mode of existing engineering students, and explores the new engineering teaching model. And then, it gets innovative ways to train qualified personnel and research conclusions.
\end{abstract}

Keywords—new engineering; innovation; practice; training mode

\section{INTRODUCTION}

In the "State Science and Technology Innovation Plan" released by the State Council during the 13th five-year period, China's scientific and technological innovation work should be closely related to the strategy guideline for innovation-driven development. And it has effectively supported the implementation of national strategies such as "Made in China 2025", "Internet +", "network powerhouse", "aerospace powerhouse", "Marine powerhouse" and the construction of the Belt and Road initiative. It gives full play to the core leading role of science and technology innovation in promoting industrial development and development of new space, moving towards medium and high end and adding new momentum for the development. In order to response to the national strategic needs, leading and supportive services will break new ground on key technologies with new technologies, new industries, new formats and new models. It would make the construction on the advantages of priority development and occupy strategic high ground in the future global innovation. The need to train a large number of new engineering and technological innovation talents will set higher requirements for the education and training of new engineering innovative talents in colleges and universities.

\section{NEW ENGINEERING}

The so-called engineering refers to the engineering discipline. Generally, people would apply mathematics, science, technology, economics, social science and other knowledge to human practice. In fact, the knowledge is not tied to each other. Whether it is mathematics, science, economics or sociology, it is ultimately provided for human beings to develop production and improve living standards in the form of technological or technological achievements (products). Technology is the core and foundation of a project. The emerging engineering education must be bound to rebuild some core knowledge. And then, the original knowledge will be upgraded.

\section{A. The Characteristics of New Engineering}

New engineering is different from the traditional engineering. It must have qualitative regularity, leading, generalized, forward-looking, cross-cutting, open, practical characteristics. And the six characteristics must be particularly emphasized in the construction of new engineering. This is also the direction and principles for transformation and upgrading of traditional engineering as well as the innovation and development of engineering education.

\section{B. New Engineering and Old Engineering}

In recent years, a large number of new specialties such as nanomaterials and technologies, new energy science and engineering, resource recycling science and engineering, internet of things projects, robotics science and engineering, and microelectronics engineering have been set up in colleges and universities. These new specialties are closely integrated with the forefront development of science and technology. And it would lead the direction of personnel training. It is veritable "new engineering". [1] However, some specialties such as mechanical engineering, electrical engineering, civil engineering, safety engineering, surveying and mapping engineering and metallurgy have trained a large number of engineering talents. Are these specialties old? Should these specialties be eliminated? We should pay more attention to the construction of these "traditional" engineering majors in the construction of "new engineering". The vast majority of those newly established professions have been influenced by these "old engineering subjects". The teachers will not be able to appear without the foundation. And teaching materials will not be published 
overnight. The training program is largely derived from the times on the basis of the cultivation plan of "old engineering". Therefore, the transformation and upgrading of traditional engineering education is as important as the construction of new engineering.

\section{New Engineering and New Economy}

The development of the new economy is guided by the revolution of new technologies. The development of new industries depends on engineering education. Then, it would provide the support for qualified personnel. In a sense, the economy can actually be regarded as social expression of technology. It is the "programming" on the basis of the value of technology. In fact, some of the most important elements that make up the economy are finance, monetary, stock and logistics. Of course, there is basic production process. They are fundamentally complex and subtle technical systems. In fact, the most primitive technology evolves step by step. [1] However, in addition to relying on the progress of new technologies, the development of new economy and new industries still has many external conditions. And these external conditions include the flow of funds, the price of resources, the stage of development and the degree of possession of existing industries, and so on. Therefore, in order to support and lead the new economy, the new engineering must provide a large pool of new technologies. That is to say, new engineering can spawn and lead the new economy.

\section{ANALYSIS ON TRAINING MODE OF EXISTING ENGINEERING STUDENTS}

In the training of engineering students, China has formed a relatively fixed training mode in recent years. That is to say, the students should have general education and basic knowledge of learning in the first and second grade. The students should have professional basic knowledge of learning in the third grade. The students should have professional courses and graduation design in the fourth grade. This training mode is to impart knowledge system. The teaching requirements are strict. Teaching plan and system is complete. The theoretical foundation is solid. However, when it comes to teaching practice, there are defects such as "emphasizing on knowledge and ignoring abilities", "emphasizing theory and neglecting practice" and "emphasizing inheritance and neglecting innovation". It is unfavorable for the cultivation of students' innovative ability. Specifically, there are some deficiencies as the following:

\section{A. Training Purposes}

In the term of training purpose, the learning of curriculum knowledge is the center. The purpose is to master knowledge. Teaching content is on the basis of the textbook. In the teaching methods, classroom teaching is subject. It is difficult to promote the main discussion of interactive teaching in a large area. The teaching process is the traditional process of preaching, teaching and solving problems. And it ignores the cultivation of students' abilities, especially the cultivation of innovative abilities. In the assessment methods, the results of the course examinations could be the basis for the evaluation on students. In this teaching mode, students are passive. It can't maximize the initiative of students. It can't cultivate the creative spirit of students.

\section{B. The Design of Curriculum System}

In the aspect of curriculum system design, the curriculum system converges. And students have little choice. Most engineering colleges switch to use credit system. The students have some rights to choose their own interested courses. However, on the one hand, they have a large proportion of required courses. The learning tasks and autonomy are limited. On the other hand, the range of courses available is narrow. There is narrow professional area. And the boundaries between the major are obvious. The theory is out of integration with practice. In the final assessment of the overall quality, the proportion of learning elective can almost be negligible. Through the elective, it can stimulate students' hobbies. Therefore, to cultivate the spirit of creativity is not ideal.

\section{Practical Aspects}

In the practical aspects, the teaching of confirmatory experiment is the main part. And the importance of cultivating students' innovative ability is not enough. Interests and hobbies are the best teachers to guide innovation. A broad system of knowledge structure is the basis of innovation. For engineering students, practice is the source of innovation. The students should discover problems, analyze problems and solve problems in practice. And it could cultivate students' innovative ability. In the current curriculum system design, the practice is mainly accomplished by the classroom experiments. Based on certain methods and steps, the vast majority of classroom experiment content is to verify certain principle or phenomenon. There is few exploration, research and open experimental content. The focus of such experiments is to develop the students' basic experimental skills, rather than the students' practical and innovative ability.

\section{WAYS TO CULTIVATE INNOVATIVE TALENTS}

Talent is the primary resource for developing and expanding the new economy. As the primary driving force for the first productive force of science and technology, the first resource for qualified personnel and innovation, higher education should play an important and special role. Engineering education is closely linked with the industrial development and mutual support. The development of new industries is based on engineering education. It could provide personnel support to deal with new technologies and new industries in the international competition and challenges. The word "innovation" was first put forward by Schumpeter in 1911, which was a combination of elements of production. And we have done something that couldn't be accomplished. It was called innovation. [2] The previous discipline settings, whether it is engineering, science or product conversion, the elements are out of relation. The innovation we are now talking about is to connect these elements together. It is a 
very important task to connect these factors well in engineering education in colleges and universities.

The innovative talents of engineering need to master the basic specialized systems. Also, they should also have creative thinking and good innovative ability. It can be seen that the existing training mode of engineering students can't meet the needs of cultivating students' creative spirit and innovative ability in terms of training objectives, curriculum system design and teaching methods. Therefore, it is necessary to develop a new training mode and use scientific methods to stimulate students' creative spirit based on the teaching students' basic knowledge. And it can develop students' creative thinking potential and cultivate students' innovative abilities.

\section{A. To Set Reasonable Curriculum System}

1) Professional curriculum system: To construct a reasonable curriculum system and develop systematical training is the prerequisite to improve students' innovative ability. The construction of the curriculum system should adhere to the principle of "thick foundation, heavy ability and innovation". The students should coordinate the relationship between basic education and ability education. The colleges and universities must try to divide the course system into several interrelated and relatively independent modules, such as basic course, professional course, practice course and extended course. The design of basic education curriculum should devote itself to expanding students' knowledge. The setting of professional courses should emphasize the internal connection among various courses. The basic courses and professional courses form broad and logically linked knowledge. With practical courses, the colleges and universities should promote the cultivation of students' abilities and stimulate students' innovative inspiration. The colleges and universities should emphasis on expanding the curriculum setting. If undergraduates want to become highly qualified personnel with strong practical ability and innovative ability, they should have a solid theoretical foundation and a wide range of knowledge. Colleges and universities should set up a wide range of high-level knowledge lectures or seminars on the frontier developments of various disciplines. Also, they should encourage the students to participate in interdisciplinary and elective courses. It could expand students' knowledge and lay a good foundation for enhancing their innovative abilities. Under the condition of circumstance, the colleges and universities should invite domestic and foreign highlevel scientists to make a report on the development of subject. The students would understand the new development and new trends of social and scientific research. This would enlighten students' innovative thinking.

2) Curriculum system of innovation and entrepreneurship education: Under the new engineering background, colleges and universities have incorporated innovation and entrepreneurship education into undergraduate education programs. And the colleges and universities should establish sound curriculum system and measures of innovation and entrepreneurship education. They would improve teaching methods and teaching contents, optimize training mode of innovation and entrepreneurship education, and reconstruct curriculum system of innovative talent of new engineering and entrepreneurship training mode. The colleges and universities will adhere to the guiding ideology of taking a piecemeal approach. According to the document of "the Notice of the Ministry of Education on Research and Practice of New Engineering" (Teach High Secretary [2017] No. 6), they should carry out the reform and practice of new engineering in local colleges and universities. With actual practice, they could make the reform and construction of engineering curriculum system of innovation and entrepreneurship education. [3] First, the colleges and universities should carry out innovation and entrepreneurship education for all students. They should open general courses such as "career planning for college students", "Introduction to innovation and entrepreneurship college students" and "career guide". The second is to open professional innovation and entrepreneurship education. It could cultivate students' innovative and entrepreneurial skills, guide students to carry out their entrepreneurial practice combined with specialties, broaden students' employment space and enhance their employability. Third, they should set up public elective innovation and entrepreneurship education. It could help students who have innovative entrepreneurial potential and interests expand their capabilities of innovation and entrepreneurship. And it would provide support for innovation and entrepreneurship projects and incubation. It would form an in-depth curriculum system of innovation and entrepreneurship education of "General Education-Professional TrainingPractical Training". And it would effectively improve the quality of personnel training.

\section{B. To Reform Teaching Modes and Methods}

In the teaching methods, the teachers should be the subject. The curriculum-centered teaching methods should be changed into teaching methods that take students as the subject. For professional basic courses and specialized courses, they should promote case-based and inferential teaching mode. The students could change passive adaptive learning to active exploration of learning. And they can change classroom teaching from imparting knowledge to teaching methods. Under the conditions, the teachers should carry out participatory and seminar teaching, encourage students to collect information, elaborate their views, and arouse students' enthusiasm for participation and research interests. With the rapid development of modern educational technology, many forms of blended learning are widely used, such as flip classroom, mobile learning, virtual reality, MOOCs, game-based learning and so on. It would be easy to meet the learning needs of students. It could fully achieve personalized learning. 


\section{To Focus on Practical Aspects and Reform the Practice}

According to the connotation of the new engineering construction and development, a large number of emerging engineering and technical personnel need to be cultivated. In the existing training programs of colleges and universities, the teaching content of engineering practice should be strengthened. The colleges and universities should focus on cultivating the engineering ability and innovation ability of engineering students. Through revising the professional teaching plan, they should highlight and strengthen the position of teaching practice.

1) To carry out various practical teaching: The colleges and universities should develop the curriculum on practice exploration, project research, writing paper, experiment, computer and the actual operation. Practical teaching should focus on training students' basic experimental skills and practical ability. The teachers should make full use of existing conditions to arrange teaching content reasonably. They should change experimental teaching from the traditional replication experiments to comprehensive and design-based experiments. The colleges and universities should provide students with the conditions. They should encourage students who have similar interests to form a team with professional teachers. And then, the students would carry out research experiments. In the teamwork, the colleges and universities would cultivate students' ability to collect information and observation ability. The students would have the ability to find and solve problems. Also, they have expression ability and collaborative spirit. Therefore, it would create innovative ability.

2) To construct off-campus practical teaching platform: The colleges and universities should construct a batch of off-campus practical teaching platforms represented by offcampus practical education bases and excellent engineers' plan training bases. Through the teaching reform and practice, they should gradually establish a new teaching system of innovative engineering talents on the basis of offcampus practical education bases.

3) To strengthen the school-enterprise cooperation: The industry-university-research cooperation is the essential requirement of engineering education. Also, it is the basic concept of new engineering personnel training. The colleges and universities should strengthen the all-round cooperation with off-campus practice teaching platform related to the enterprises in scientific research and technical services. They should train the technical backbone for enterprises to solve the actual problems. [4] According to the demand of enterprise development, it actively adjusts the training mechanism of higher education, grasps the opportunity of new technology innovation and new industry development, and vigorously promotes the teachers to transform the latest scientific achievements into the key technology of new technology, new format and new industry. It would realize the transformation from traditional economy to new economy.
4) To focus on graduation design: During the process of completing graduate design, the teacher should control topic selection, process and defense. According to their own strengths, hobbies and knowledge structure, the students should attempt to choose their own research direction of graduation design. The teachers and students should analyze the subject together. And they should further refine the content of the study. During the process, the teachers should fully respect the autonomy of students. The students should develop their own research methods, experimental programs and technical routes. They should discuss the problems in time. And the teachers should guide students to make their own amendments. [5] The graduation reply should focus on students' research process and ideas. It would review the paper and pay attention to research results, such as experimental programs and applications. According to evaluation process, the practical ability and creativity of the students could be demonstrated in graduation design process.

\section{To Enhance the Quality of Teachers and Practical Ability and Protect the Cultivation of Students' Innovative Ability}

As one of the key elements in teaching activities and the specific implementer of teaching activities, the qualities and abilities of teachers have direct impact on the quality of qualified personnel. At present, colleges and universities focus on stylized basic teaching ability and examination in the assessment of teaching skills. This assessment on the basic teachers is appropriate. It could ensure that teachers can teach the textbook knowledge to the students. [5] The teachers who pass the assessment can become the educators. However, there is a big gap from cultivating the students' innovation thinking and ability. A teacher that masters the basic professional knowledge, has weak practical ability, and does not have open-mindedness can't develop students' creativity. It would have influence on the development of students' innovative abilities. In order to adapt to the training of new engineering talents, teachers also need to go out and have communication frequently. The teachers should have exchanges with brother colleges and universities and famous foreign universities. Of course, teachers can also lead students to conduct exchange and study to fully broaden students' horizons. They can lead students to enter the construction site or design institutes to have internships. It enables students to use knowledge. And the students would know what they have learned.

\section{CONCLUSION}

In the background of new engineering construction, the reform and development of engineering education in colleges and universities are facing great opportunities and challenges. The colleges and universities in Xi'an city should also advance with the times. Leaded by "Fudan consensus" and "big action", the colleges and universities should constantly have the research and practice on new engineering. The colleges and universities should explore the training of innovative engineering talents, promote the construction of new engineering, and have the study and practice. And then, 
they could constantly enrich and improve the training mode. The colleges and universities should take the initiative to align with the development goals of the region, and focus on the principle of "strengthening moral education and cultivating people". They should face the challenges in the future. They should know the needs of the world and the industry. The colleges and universities must improve the mode of cultivating innovation and entrepreneurship talents, and deepen the reform and innovation in higher engineering education. Economic development and industrial upgrading play a supporting role in building an industrial powerhouse.

\section{REFERENCES}

[1] Zhao Ji. Construction of new engineering and innovation of engineering education $[\mathrm{J}]$. Research in Higher Education of Engineering. 2017.05: 13-18

[2] Chen Jianzhong. Thinking on education reform and innovation of vocational and technical engineering under the background of "engineering" [J]. China Management Informationization. 2017,11: 53-59

[3] Shao Fude. Training model of innovation and entrepreneurship of new engineering talents in local colleges and universities [J]. Technology and Entrepreneurship. 2017.10: 62-64

[4] Gong Xiaojia. Exploration on new engineering innovative talents in practice teaching in comprehensive colleges and universities [J]. Higher Education Press .2017.12: 141-142

[5] Lu Biying. The mode of training innovative engineering talents [J]. China Electric Power Research. 2013.07: 19-20 